\title{
The development of a change agent identification framework for South African change agents
}

\author{
by Marzanne van der Linde-de Klerk ${ }^{*}$, Nico Martins \\ and Marie de Beer
}

\begin{abstract}
The main aim of this research project was to develop a theoretical change agent identification framework that could enable organisational change management specialists to identify change agents more effectively in large organisations that are undergoing change. To date, little research has been conducted into the best way to identify change agents. Change agents can play a significant role in effectively assisting co-employees to adapt to change and in eliminating resistance. The sample of change agents utilised in this research project comprised employees at a large South African utility organisation who were affected by change themselves but nevertheless helped to communicate key messages to other affected employees and supported them throughout the change process. These change agents played a significant role in helping to develop a comprehensive change agent identification framework that focuses on those elements to be taken into account when selecting individuals in an organisation to serve as change agents. A thorough 12-step empirical research process which included both a qualitative and a quantitative approach was followed. The qualitative process and results constitute the focus of this article.

The literature findings contributed towards a comprehensive understanding of the role of change agents, as well as of the elements that should form part of a change agent identification framework to be used as a basis for selecting change agents.
\end{abstract}

Key words: organisational change, change management, change agent identification framework, personality traits, change agent network, occupational personality profile

\section{Introduction}

The marked tendency for change to be accompanied by negativity, uncertainty and doubt was acknowledged as early as the 16th century. In 1513, the researcher and philosopher, Niccolo Machiavelli, stated, "There is nothing more difficult to plan, nor more doubtful of success or more dangerous to manage than the creation of a new order of things" (Rogers 2003:1).

\footnotetext{
Dr $M$ van der Linde-de Klerk is a former PhD student of the Department of Industrial and Organisational Psychology at the University of South Africa..

** Prof N Martins and Prof M de Beer are attached to the Department of Industrial and Organisational Psychology at the University of South Africa.
} 
Change has always been part of the human condition and is particularly noticeable at present, as humankind engages in increased global competition, experiences technological advancement and contends with declining resources. Some of the less favourable implications of world-wide change are global warming, overpopulation, increased ineffectiveness of social institutions and even pollution (St-Amour 2001).

The only significant difference between change as it was experienced in the past and its current manifestation is the pace at which it is taking place. The pace of change is even expected to increase, which will affect every facet of life. In many instances, change is so rapid today that people do not have time to adapt before the next change is upon them. Sometimes change is planned and people have sufficient time to prepare themselves in advance, but in other instances change is unexpected and people have to make immediate adjustments in response (Laycock 2002). According to Van Tonder (2004), the pace of change is much faster now than in the 1980s and 1990s.

Successfully implementing and sustaining change in an organisation requires the formulation of intended outcomes in order to change the organisation's bottom line. The manner in which the proposed changes are implemented has a profound impact on the individuals in the organisation. Today, most organisations have accepted that the only constant is change. Continuous change is often viewed as "white-water turbulence" which forces the leaders of an organisation to examine their vision and values and the essence of what they stand for (Turner 2012).

Research conducted by Moran and Brightman (2000) gave rise to a number of observations. Firstly, change is non-linear and often seems confusing and endless. Secondly, a planned change process makes it possible to connect with multiple stakeholders in an organisation. Thirdly, change can be either a top-down or a bottomup process. In the case of top-down change, clear direction is provided, whereas the bottom-up approach encourages participation and generates support. Fourthly, the more significant organisational change is, the more crucial it becomes to create opportunities for employees to revise and adjust their own values and beliefs accordingly (Moran \& Brightman 2000).

Organisational change occurs mainly in the context of failure or adjustment of some kind. In organisations, change involves the difference in the way an organisation functions, who its members and leaders are, what form it takes and/or how it allocates its resources (Huber \& Glick 1993). St-Amour (2001) comments that organisational change usually occurs in response to mergers, acquisitions, outsourcing, downsizing, restructuring or streamlining. Organisations employ change management specialists to manage the impact of change (for example, process and/or technology adjustments or changes) in the organisation (Stassen 2006). Change management specialists therefore work with both human resource and organisational elements of change.

No matter what the reasons for planned, organisational change in organisations, the effects on employees may be either beneficial or negative - to both the organisation and its employees. If employees do not accept the proposed changes in the organisation and fail to realise the benefits, the organisation could suffer tremendously or even decline from being a market leader to fighting simply to remain in the market, without any competitive advantage (Rogers 2003).

In this context, the objective of organisational change management is to maximise the collective benefits for all people involved in change and minimise the risk of failure in implementing the change (Stassen 2006). This process can be driven by organisational change management specialists. Because of the sensitivities and complexities of the change management specialist's job, individuals in this position 
need to have relevant knowledge and experience if they are to fulfil this role and to drive change meaningfully in the organisation (Borysowich 2006).

\section{Background to the study}

These days organisations are increasingly employing change specialists to manage change so as to help employees become accustomed to the new order of things. In many instances industrial psychologists act as change management specialists in organisations. They are regarded as the most suitable people for the task, simply because they understand that employees are going to react differently to change and that everyone has fundamental needs that have to be met. Change often involves loss, expectations that need to be managed realistically and fears that have to be dealt with appropriately (Rouse 2009).

Many industrial and organisational psychologists specialise in change management and, through experience and knowledge, become change management experts in organisations, usually advising on how to implement change in the way that is least disruptive for the organisation (Wertheimer 2001). Stassen (2006) observes that change management specialists understand that some individuals anticipate a better future but regret that which will be left behind, while some want to turn around and go back to what they are used to. Both positive and negative behaviour should therefore be managed in a way best suited to the organisation and its culture.

The more people are affected, the more difficult it becomes for organisational change management specialists to manage a process of smooth transition and to create an environment that is conducive to improving change readiness (Rogers 2003). Managing change has been described by numerous successful businesspeople as one of the most important skills required by managers and employees today (Rogers 2003).

In large corporate organisations it sometimes seems impossible to manage change, as there are too few change management specialists and too many employees affected by change. If change management specialists are not visible in all areas of the business, and if they are not communicating and liaising directly with the affected employees, how can employees be prepared for change and people motivated to embrace change rather than to reject it?

Change management specialists cannot be everywhere. However, organisations could have individuals, acting as change agents, spread throughout the organisation to serve as the eyes, ears and voice of change management specialists. If these representatives are able to keep their fingers on the corporate pulse, it will be possible to deal with issues, concerns and questions much sooner and implement solutions accordingly. It could be highly advantageous in the long run to appoint individuals on the ground as agents of change in order to ensure a smooth transition with which employees are comfortable and about which they can remain optimistic throughout (Recklies 2001).

While their functions are similar, there is a difference between a change management specialist and a change agent. As indicated earlier, a change management specialist is someone responsible for managing the impact of change on the organisation. This person is concerned with both the human resource and organisational aspects of change. As early as 1987, Rogers and Kincaid (1987) described change agents as people with one foot in the old world and one foot in the new world, helping employees to cross the bridge to the new world, while providing support throughout the journey. 
According to Tearle (2007), a change agent could be compared to a medical doctor who diagnoses the real problem and then proposes clear, well-directed solutions. From diagnosis to the achievement of the desired end state, the change agent plays the roles of facilitator, designer, educator, marketer, observer and someone who could influence staff members. Employees who are passionate about change can serve the organisation as change agents, but they will then have to report to, and be managed by, a change management specialist.

To date, it has been unclear what typical personality traits, skills and knowledge individuals should display to be effective as change agents (McNamara 2007). The aim of the research discussed in this article was therefore to answer the following research question: What are the dimensions and supportive elements that constitute a valid change agent identification framework? An in-depth literature study was conducted in order to obtain as much information as possible in this regard. After relevant literature had been collected and analysed, a framework of key dimensions and supportive elements was compiled to assist in the identification of future change agents. As no such framework existed previously, it is hoped that organisations will be able to use this framework to become more effective in identifying individuals to act as change agents, and to help them manage change with greater ease and efficiency (Wertheimer 2001).

\section{Literature review}

\subsection{Organisational change management}

There are many definitions of organisational change management. Those most applicable to this research project are cited below.

Porras and Robertson (1992:723) define change as "a set of behavioural sciencebased theories, values, strategies and techniques, aimed at the planned change of the organisational work setting for the purpose of enhancing individual development and improving organisational performance through the alteration of organisational members' on-the-job behaviours". This definition indicates that a shift would take place as current organisational behaviour becomes more closely correlated with ideal organisational performance in response to improvement in some of the capabilities and skills of the employees.

There are many definitions of change - the majority of which are interlinked.

Ford and Ford (1994 see change as a sequence of activities, emanating from disturbances in the stable force field surrounding the organisation, object or situation. Van de Ven and Poole (1995:511) define change by looking at its end result: "Change, one type of event, is an empirical observation of difference in form, quality or state over time in an organisational entity." Change can be viewed from an individual perspective, because new human behaviour may be required. It can also be seen from a business perspective, because it may imply new business processes or systems. From a societal perspective it can be viewed in terms of changes in public policies or legislation (Worren, Ruddle \& Moore 1999).

This indicates that change occurs in all areas of life and that change should be understood in the context in which it occurs.

Powell (2002:2) has the following to say about the shift in technology: "It will be messy and it will be confusing, and we will get a lot of it wrong and we'll have to start over, but that is the creative process that is the evolutionary process." Planned change is usually linear, because it focuses on all the steps in sequential order right through to 
the final step. However, change is usually implemented in just the opposite way - it is messy, deadlines are not always met, people do not cooperate and unexpected decisions are made because of unanticipated consequences. Implementing change is not always a smooth process. Although this process is usually messy, it is crucial to have a plan in place in order to remain focused on the change goal and end state (Burke 2002).

Van Tonder (2004) provides a generic view by stating that change can be seen as a process and that change is evident in the difference reflected by a specific state. This indicates that change cannot be implemented successfully overnight. It is a process that requires a lot of preplanning before the execution phase is entered into. According to Robbins (2005), change occurs when something becomes different, while planned change involves change activities that are intentional and goal-oriented. Planned change is ultimately concerned with changing individual behaviour in order to respond to the changes that the environment generates.

Characteristics or reasons for organisational change were also offered by many researchers in the field. Laycock (2002) provided a perspective from an employee training and development angle, by stating that organisational change would not occur or be necessary if individuals did their jobs correctly and thoroughly in the first place. Laycock goes on to state that organisational change usually occurs in response to the failure of people to do what is expected of them. This failure results in the organisation's having to adapt continuously.

Hailey (2001) states that the process of change may take many years. Change, therefore, does not need to be all-inclusive and could be implemented in increments over a period of time. Doyle, Claydon and Buchanan (2000) disagree about this form of change management, stating that successful change does not require milestones in the change planning phase, but rather in the implementation stage of the change - and that implementation should take place all at once (the "Big Bang" approach).

Quy Nguyen (2001) disagrees with both of these approaches to change management, stating that each organisation needs to find its own internal change rhythm that allows for some alternatives between rapid and moderately paced change, without losing synchronisation or control in the process. Change management could be viewed as a process of continuously renewing the organisation's direction, structures and capabilities in order to satisfy the needs of its internal and external customers (Moran \& Brightman 2000).

Mastering change management techniques is vital, because the marketplace can change overnight and technological advances can occur daily. Change management may also refer to the introduction of changes in a planned and managed or systematic fashion. It involves the effective implementation of new methods and systems in an organisation, under the control of the organisation itself (Bolognese 2002).

Creasey (2007) provides a definition of organisational change management used by many organisations to explain the concept to their employees in the 21st century. His definition stresses that change management comprises the process, tools and techniques required to manage the people side of change, so as to achieve required business outcomes. Change management incorporates organisational tools to help individuals make successful personal transitions, resulting in the adoption and realisation of change.

This selection of definitions reveals the wide range of views on change management. As indicated earlier, every organisation has different reasons for undergoing change. 
Ideally, therefore, each organisation should analyse its own situation and decide which approach would be most applicable, while each organisation is unique and should therefore apply a change model suited to its environment and circumstances.

\subsection{The role of change agents}

Researchers have been considering the role of change agents since the 1980s. Schein (1987) states with reference to all levels of change in an organisation that the change agent is regarded as a helper who intervenes in the process by playing the role of facilitator. For Ticky and Devanna (1990), a change agent can be anyone affected by change, to the extent that the individual's personal involvement in reframing contributes to the successful outcome of the change management process.

Pettigrew and Whipp (1991) describe change agents as individuals who operate at various levels within an organisation, as this allows for both operational and strategic change capacity.

In the opinion of Saka (2003), organisational change agents are managers who shape the conditions for change. Saka also emphasises that managers, unlike consultants, are the organisation's "internal" change agents, because they have insight into the overall organisational goals and vision. A manager who is a change agent has a beneficial role to play in large-scale transformation, as this person has the capacity to reconfigure an organisation's roles, responsibilities, structures, outputs, systems and resources.

Burnes (2004:669) refers to change agents as "the people responsible for directing, organising and facilitating change in organisations". This can be a difficult task, especially in the case of large bureaucratic organisations. The definitions most applicable to the context of this research project were firstly formulated by De Caluwé and Vermaak (2002), who stated that change agents could be managers, consultants or employees of an organisation, or even network partners.

Secondly, Cheung, Jurman, Maguigad and Slaughter (2007:9) provide the following definition: "Change agents can be found in all levels of an organisation. They can be leaders, managers or employees. A change agent is someone who supports the need for change, is committed to championing the cause and motivates staff in their respective areas to see the benefits thereof."

Van der Linde-de Klerk (2010) indicates that change agents are those individuals across all levels of an organisation who have experienced the impact of organisational change themselves, who actively support the reasons for change and serve as catalysts to assist people in instilling new behaviour, so as to adapt to change effectively.

Although the above discussion indicates a range of views on the identity and role of organisational change agents, most of the researchers cited agree that the core functions of these individuals are to drive change within the organisation.

Saka (2003) is of the opinion that it would be unwise to attempt significant change without designated change agents - especially in cases where large numbers of employees are affected by change. By appointing change agents to help to measure the readiness levels of affected employees, monitor their wellbeing and resolve issues and concerns of employees at ground level, organisations could ensure the early removal of many obstacles (Smith 2005).

Change agents have been described as those individuals within organisations who provide guidance to team members and are usually regarded as people to whom others 
listen (Smith 2005). In many organisations, a group of change agents is referred to as a "change agent network" (Hutton 1994).

Hutton (1994) and Accenture (2007) provide some valuable insights into the role of change agents. These authors indicate that the more aware change agents are of any information that could potentially affect them as a result of changes, the better they are able to disseminate the information to employees, in order to keep everyone informed and feeling valued as part of the business. The closer a change agent is to new information that is released, the sooner such agent will be able to communicate the impact and proposed changes to other colleagues.

According to Massey and Williams (2006), the change agent may be seen as someone who is selected to help employees cope with change that is usually driven by a specific initiative or project. The focus is therefore specific and the change agent usually knows what is expected of him or her. The number of change agents selected usually depends on the size of the organisation, the number of employees affected and the extent of the change.

Employees who are fulfilling the role of change agents and who are also personally affected by the change are more likely to question the value of changes and the answers they obtain could equip them with expert knowledge, and enable them to answer all or most of their peers' questions (Senge, Kleiner, Roberts, Roth, Ross \& Smith 1999). Ideally, a change agent should be able to find a balance between being a technical expert, having all the answers and acting as a process facilitator, while allowing employees to find their own answers by providing some form of guidance (Paton \& McCalman 2000).

Welch and Welch (2008) take an interesting view of what being a change agent constitutes. For these authors, change agents see a future that no one else does and that vision will not allow them to rest. They do not take the lead in change because it "makes sense" or because change is "necessary"; they take the lead in effecting change because they believe that, in order to survive and win, their organisation must get ahead while approaching "discontinuity". Welch and Welch further state that possibly the greatest misconception about change agents is that they are "lone rangers". In fact, research has indicated that the most effective change agents motivate, lead and inspire, while surrounding themselves with large numbers of people so that effective change is realised.

In the course of the literature review, personality traits, skills, knowledge and experience were identified as dimensions that should be taken into consideration in selecting people with the potential to act as change agents.

For the purposes of this research project, the ideal profile refers to the ideal personality traits that someone should possess, in order to be identified as a change agent capable of driving and managing change in such agent's own business area. The above information was obtained by means of a literature search.

For the purposes of the empirical research conducted, it was of crucial importance to understand the ideal personality traits and skills required by change agents, so as to ensure that people who are to act as change agents are identified in accordance with the correct requirements. The literature findings on the key personality traits of change agents are tabulated below.

\subsubsection{The ideal profile}

The table below provides information on some key personality traits that change agents should possess: 
Table 1

Change agent personality traits

\begin{tabular}{|l|l|}
\hline \multicolumn{1}{|c|}{ Personality traits } & \multicolumn{1}{c|}{ Source } \\
\hline The ability to deal with complex issues & Hutton (1994), Dunphy \& Stace (1993) \\
\hline Integrity & Hutton (1994) \\
\hline Being respected & Hutton (1994) \\
\hline Being a team player & Hutton (1994), Tearle (2007) \\
\hline Patience & Mott (2000), Hutton (1994) \\
\hline Persistence/Persuasiveness & $\begin{array}{l}\text { Hutton (1994), Tan \& Kaufmann (2000), Dunphy \& Stace } \\
\text { (1993) }\end{array}$ \\
\hline A sense of humour & Tearle (2007), Katzenbach (2008), Hutton (1994) \\
\hline Honesty & Hutton (1994) \\
\hline Trustworthiness & Perme (1999), Hutton (1994), Tearle (2007), K Jha (2007) \\
\hline Reliability & Hutton (1994), Burnes (2004) \\
\hline Being positive/optimistic & $\begin{array}{l}\text { Tearle (2007), Katzenbach (2008), Hutton (1994), Tan \& } \\
\text { Kaufmann (2000) }\end{array}$ \\
\hline Enthusiasm & Hutton (1994), K Jha (2007), Tan \& Kaufmann (2000) \\
\hline Being confident & Tearle (2007), Hutton (1994) \\
\hline Risk-taking & Hutton (1994) \\
\hline Having a political nose & $\begin{array}{l}\text { Hutton (1994), Wertheimer (2001), Recklies (2001), Tan \& } \\
\text { Kaufmann (2000) }\end{array}$ \\
\hline Assertiveness & Powers (2003) \\
\hline Creativeness & Tearle (2007), Katzenbach (2008), K Jha (2007) \\
\hline Caring & Tearle (2007), Katzenbach (2008), K Jha (2007) \\
\hline Empathy & Arrata, Arnaud \& Kumra (2007) \\
\hline
\end{tabular}

Following the same process as for the identification of personality traits, a number of important change agent skills, as indicated by various researchers in the field, were identified. They are summarised in the table below.

Table 2

Change agent skills

\begin{tabular}{|l|l|}
\hline \multicolumn{1}{|c|}{ Skills } & \multicolumn{1}{c|}{ Source } \\
\hline Interpersonal skills & Hutton (1994), Mott (2000), Tan \& Kaufmann (2000), Wertheimer (2001) \\
\hline Communication skills & $\begin{array}{l}\text { Hutton (1994), Perme (1999), Wertheimer (2001), Arrata, Arnaud \& Kumra } \\
\text { (2007), Recklies (2001), Canterucci (2000), Tan \& Kaufmann (2000) }\end{array}$ \\
\hline Listening skills & $\begin{array}{l}\text { Hutton (1994), Powers (2003), Canterucci (2000), Mott (2000), Tan \& } \\
\text { Kaufmann (2000) }\end{array}$ \\
\hline Conflict-handling skills & Hutton (1994), Arrata, Arnaud \& Kumra (2007) \\
\hline Facilitation skills & Wertheimer (2001), Powers (2003), Tearle (2007) \\
\hline Networking skills & Accenture (2007), Recklies (2001) \\
\hline Influencing skills & Accenture (2007), Recklies (2001) \\
\hline
\end{tabular}

To summarise: Change agents should ideally have a number of specific skills and, as indicated by Keep and Mayhew (1995), people can be trained to learn and develop certain skills. People should therefore receive a proper education in order to develop their skills appropriately.

All the literature findings on change agent knowledge are summarised in the table below. 
Table 3

Change agent knowledge

\begin{tabular}{|l|l|}
\hline \multicolumn{1}{|c|}{ Knowledge } & \multicolumn{1}{c|}{ Source } \\
\hline Diagnostic models of change & Keep \& Mayhew (1995), Hayes (2002) \\
\hline Process change models & $\begin{array}{l}\text { Keep \& Mayhew (1995), Hayes (2002), Mitchell \& Young } \\
(2001)\end{array}$ \\
\hline $\begin{array}{l}\text { Understanding of the organisation and its } \\
\text { culture, customers, vision and mission }\end{array}$ & $\begin{array}{l}\text { Mitchell \& Young (2001), Tan \& Kaufman (2000), Keep \& } \\
\text { Mayhew (1995) }\end{array}$ \\
\hline Ways to manage resistance to change & Tearle (2007), Tan \& Kaufman (2000) \\
\hline Overcoming barriers to change & Tan \& Kaufman (2000), Morgan (1996), Tearle (2007) \\
\hline $\begin{array}{l}\text { Suitable communication methods and } \\
\text { approaches }\end{array}$ & $\begin{array}{l}\text { Keep \& Mayhew (1995), Hayes (2002), Mitchell \& Young } \\
\text { (2001), Tearle (2007), Tan \& Kaufman (2000), Morgan } \\
(1996) .\end{array}$ \\
\hline
\end{tabular}

The procedure or tools used in the selection of change agents could be customised for each division within the organisation, depending on where the change agent is located in the organisation and taking into consideration the nature of the change facilitation work such change agent will be asked to accomplish (Strebel 1998).

According to Strebel (1998), the two most effective and frequently used methods for selecting change agents are:

- questionnaires; and

- nominations by the respective line managers.

Where questionnaires are used, the organisation selects an appropriate questionnaire that will help to identify potential change agents in accordance with its needs. Many organisations ask employees affected by change to complete a change-readiness questionnaire. They then identify those individuals with high change-readiness scores as potential change agents (Strebel 1998).

In instances where questionnaires are not used, potential change agents are identified via nominations by immediate managers or supervisors. These managers usually nominate individuals who, in their view, have influential abilities, communicate well with others and have strong relationships with their colleagues. It is important to understand that no individual nominated to act as a change agent should be forced to fulfil this role. It should be voluntary and the individuals must have a clear understanding of what is expected of them (Strebel 1998).

Although questionnaires and/or nominations are already utilised to select change agents, no comprehensive change agent identification framework is in use as yet. A framework of this kind would ensure that the correct characteristics are evaluated when change agents are selected. The next section provides the methodology used in the compilation of this framework.

\section{Research design}

\subsection{Research approach}

A combined qualitative and quantitative research approach was followed for the overall research project. This method is referred to as a multi-phased approach, as described by Creswell (1994). The research started with a quantitative process and then switched to a qualitative process before concluding with a further quantitative process, aimed at validating the information yielded by the qualitative process. The focus of this research 
article is on the qualitative approach followed, as well as on the results it produced, which were used to compile a change agent identification framework.

A triangulation approach was adopted for the qualitative research phase of this research project. This comprised the following:

- the use of a survey questionnaire;

- a concept-mapping process; and

- a change agent identification framework.

The theoretical underpinnings of these methods, as well as their practical application, are discussed in detail in this section.

According to Mouton and Marais (1994), triangulation is the use of multiple methods of data collection with a view to increasing the reliability of observations. Neuman (2002) explains that there are several types of triangulation, the most common being triangulation of measure. This type of triangulation refers to multiple measures of the same phenomenon, which are achieved by measuring something in more than one way. This allows the researchers to analyse various aspects of a specific phenomenon.

The triangulation approach was selected for this research project because it provided a comprehensive platform for the development of a change agent identification framework. The triangulation approach helped researchers to obtain information from various sources (literature, a questionnaire and a workshop attended by subject specialists), so that they could confidently compile elements of the framework they could use to select change agents more effectively.

The aim of this research was therefore to answer the following research question: What are the dimensions and supportive elements that constitute a valid change agent identification framework?

\subsection{Research strategy}

One of the researchers' key theoretical aims was to determine the key behaviour and personality traits to be considered when identifying change agents. The information obtained from the literature study indicated why it is important to identify change agents, and what characteristics, personality traits, skills and knowledge they should possess in order to be considered effective in their role. This information was used to compile a qualitative perception questionnaire.

Key focal areas that could form part of a change agent identification framework were identified from the literature. Each main focal area represented a group of associative descriptive elements identified in the literature. As indicated previously, little research has been done in this field and, to ensure that all possible factors and dimensions were considered, the researchers had to rely heavily on qualitative and quantitative information obtained from the South African sample of participating change management specialists.

The following instruments and strategies were used in the qualitative triangulation approach:

- Exploratory qualitative perception questionnaire: After the literature findings had been analysed, a qualitative perception questionnaire was developed. This questionnaire was exploratory in nature because no existing standardised questionnaire was available and therefore open-ended questions were used to determine the perceptions of experts in the field. These experts were change management specialists who had been working for some time as external consultants at the organisation at which the research project was undertaken. 
- Concept mapping: This is a method of clarifying and describing people's ideas by means of graphical representation. Mapping concepts in graphic form makes it easier to understand the relationships between them, and this technique is especially useful in the development of a conceptual framework (Trochim 2002). Fifteen internal change management specialists participated in the process to verify which elements should form part of a change agent identification framework and which elements should be eliminated. This was done by considering and discussing the elements in the focus groups that had emerged from the qualitative perception questionnaire.

- Change agent identification framework: The results of the concept-mapping process were analysed and a change agent identification framework was developed.

\subsection{Research methodology}

\subsubsection{Research setting}

Exploratory qualitative perception questionnaire: The questionnaire was e-mailed to 30 external change management consultants from consultancy organisations who had been working at the organisation during the period in which the research was conducted. Although this was not a case study approach, it was relevant to distribute the questionnaire to these people, as they showed a comprehensive understanding of the organisation and its dynamics. These change management specialists were also included in the research project because they were considered to be familiar with the change management process, the required ideal change-readiness levels of employees affected by change and the factors resulting in resistance or readiness to change.

Fifteen completed questionnaires were returned electronically to the researchers. The respondents had been asked to provide information on various dimensions which they believed should form part of the profile of change agents. All the questions were therefore open-ended, to avoid limiting the input obtained from these participants. Participants were also required to provide some biographical information. The purpose of the questionnaire was to determine which elements experienced change management experts considered important to include in a change agent identification framework. As a guideline, a number of suggestions were made to the participants regarding possible dimensions that had been identified from the literature for inclusion in the framework.

Concept-mapping workshop: Change management specialists within the organisation, who were generally involved in large-scale projects and served as internal consultants to the business, were invited to participate in a concept-mapping workshop. All 21 divisional change management specialists in the business received an e-mailed invitation to participate in the content-mapping exercise. Of these, 15 accepted and attended the workshop. The group of internal change specialists who participated in the focus group or concept-mapping workshop were allowed to be creative and to generate, sort and prioritise ideas.

A focus group session held with internal change management specialists who had a number of years' experience in the field played a vital role in discussions on the appropriateness of each element. The assumption was that these specialists might be able to provide other suggestions about elements or dimensions that should be included in or excluded from the proposed framework and that should be taken into account by the researchers. Conducting a focus group session reduces the risk of excluding important dimensions or elements (Trochim 2002). 


\subsubsection{Sampling of change management specialists}

The sample groups were established via purposive sampling rather than via random assignment. Purposive sampling falls into the category of probability sampling and relies on the researcher's judgement (Ryan 2011). In this case, the researchers carefully selected the sample groups of participants to take part in this research project on the basis of their specific experience in and knowledge of the field of study.

The sample groups comprised the following:

- A group consisting of change management specialists, working as external consultants in project management environments. A sample group of 30 was initially envisaged, but only 15 exploratory qualitative perception questionnaires were returned.

- A group comprising 15 change management specialists in a large organisation, predominantly involved in large-scale, organisation-wide projects as internal consultants to the business. These participants were invited to take part in the concept-mapping exercise.

\subsubsection{Data collection methods}

In the qualitative research phase, different data collection methods were employed in respect of the two sample groups. The exploratory qualitative perception questionnaire was sent to the sample group by e-mail. The group was asked to complete the questionnaire and e-mail it back to the researcher. During the concept-mapping workshop, the second sample group was split into smaller focus groups, each of which discussed and verified the information obtained from the completed qualitative perception questionnaire.

\subsubsection{Data analysis}

The results of the open-ended questions and subsequent concept-mapping process served as inputs for the change agent identification framework that was developed. This framework comprised four dimensions and their supportive elements, as identified by the questionnaire and agreed to at the concept-mapping workshop. The process that was followed to confirm the elements to be included in the framework was based on the alignment of the questionnaire and concept-mapping findings with the results obtained from the literature review. The next section explains which findings were aligned with the literature findings.

\section{Results}

To make it possible to develop a comprehensive theoretical change agent identification framework, it was necessary to carefully consider and compare information obtained from a study of the literature, from feedback obtained from the qualitative perception questionnaire and from the discussions between the change management specialists during the concept-mapping workshop.

By comparing the concept-mapping workshop results with the literature findings, it was possible to determine which dimensions or elements were considered important by the specialist sample group and researchers in the field. These dimensions or elements were then used as part of the change agent identification framework. The following process was used to determine which elements should form part of this framework:

- The researchers short-listed all the dimensions which, in the opinion of the sample group, should make up the change agent identification framework. The following eight proposed dimensions were short-listed, to be verified at the concept-mapping 
workshop: Knowledge, ability, skills, level of commitment, availability and willingness, personality traits and experience.

- These results were documented to enable the concept-mapping workshop participants (a different sample group) to review the information provided by the first qualitative perception questionnaire sample group. The participants indicated that, in their view, the following dimensions should form part of such a framework: Level of commitment, willingness, availability and personality traits.

The findings of the qualitative questionnaire indicated that the following proposed dimensions should be included in a change agent identification framework: Personality traits, skills, knowledge, experience and change curve readiness levels. The workshop attendees argued that it was not regarded as essential to include skills, knowledge, experience and change-curve readiness in the identification framework itself. They agreed that it was preferable to focus instead on skills, knowledge and experience only after people had been identified as change agents.

Although they proposed that these elements should not be included in the framework, the workshop attendees did identify the elements they considered necessary to ensure that the change agents who were identified would obtain the knowledge they required for self-development and for driving change effectively. It was also proposed that change agents should be exposed to different change and transformation scenarios in an organisation, in order to gain the experience they needed to become more effective drivers of change.

Change curve readiness levels were not regarded as important elements to include or even to focus on after change agents had been identified. The reasons were that change readiness scores work in parallel with the timelines of a specific project and that the more freely information is shared throughout the project, the better prepared employees are likely to be for change. The workshop attendees also concurred that readiness levels for change should not be considered when identifying change agents. Instead, change agents should be provided with a reliable change readiness assessment tool to determine the change-readiness scores of their co-workers.

It was also agreed that it was necessary for change agents to undergo training soon after appointment, so that they could obtain the correct knowledge and acquire the necessary skills before beginning their task.

The workshop participants placed strong emphasis on the following:

- It is imperative for a change agent to be directly affected by the change initiative for which such change agent has been identified, because the individual would then share the "pain" that co-workers are experiencing.

- If the change agent is personally affected by change, it would help such change agent to explain the "What-is-in-it-for-me" element, influencing peers to accept change and to provide the change management team with valuable information on possible issues and concerns identified in their area of work.

In all, 12 personality traits were identified during the concept-mapping workshop. All 15 workshop participants concurred that these personality traits were important for anyone acting as a change agent. When the findings of the concept-mapping workshop were compared with the literature findings, they were found to overlap with regard to the personality traits of assertiveness, honesty, persuasiveness, integrity and optimism. This indicated agreement between both researchers in the field and the sample group of internal change management specialists about the importance of these personality traits for change agents (see table 4). The 12 traits identified at the workshop were therefore included in the framework. 
Table 4

Personality traits: Results from the concept-mapping workshop and literature survey

\begin{tabular}{|lll|}
\hline & Findings from concept-mapping workshop & \multicolumn{1}{c|}{ Findings from literature } \\
\hline $\mathbf{1}$ & Willingness & Ability to deal with complex issues \\
$\mathbf{2}$ & Integrity and honesty & Integrity \\
$\mathbf{3}$ & Assertiveness & Assertiveness \\
$\mathbf{4}$ & Flexibility & Team-player \\
$\mathbf{5}$ & Approachability & Patience \\
$\mathbf{6}$ & Perseverance & Sense of humour \\
$\mathbf{7}$ & Influence/Persuasiveness & Persistence/Persuasiveness \\
$\mathbf{8}$ & Open-mindedness & Honesty \\
$\mathbf{9}$ & Good listening skills & Trustworthiness \\
$\mathbf{1 0}$ & Emotional maturity - change to self-awareness & Caring \\
$\mathbf{1 1}$ & Optimism & Positive attitude/Optimism \\
$\mathbf{1 2}$ & Sociability & Reliability \\
& & Enthusiasm \\
& & Confidence \\
& & Risk-taking \\
& & Political nose \\
& & Respected \\
& & Creativity \\
& & Empathy \\
\hline
\end{tabular}

In all, 12 change agent skills were identified during the concept-mapping workshop. All 15 workshop participants agreed on the importance of these skills for anyone acting as a change agent. When the concept-mapping workshop findings were compared with the literature findings, an overlap was identified in respect of the following skills: Interpersonal skills, conflict-handling skills, facilitation skills, networking skills and influential skills (see table 5). This indicated agreement between both researchers in the field and the sample group of internal change management specialists on the importance of these skills for change agents.

Table 5

Skills: Results from the concept-mapping workshop and literature survey

\begin{tabular}{|lll|}
\hline & Findings from concept-mapping workshop & \multicolumn{1}{c|}{ Findings from literature } \\
\hline $\mathbf{1}$ & Intrapersonal skills & Interpersonal skills \\
$\mathbf{2}$ & Influential skills & Influential skills \\
$\mathbf{3}$ & Selling skills & Listening skills \\
$\mathbf{4}$ & Deductive reasoning skills & Communication skills \\
$\mathbf{5}$ & Networking skills & Networking skills \\
$\mathbf{6}$ & Conflict-handling skills & Conflict-handling skills \\
$\mathbf{7}$ & Facilitation skills & Facilitation skills \\
$\mathbf{8}$ & Attentive listening skills & \\
$\mathbf{9}$ & Problem-identification skills & \\
$\mathbf{1 0}$ & Problem-solving skills & \\
$\mathbf{1 1}$ & Negotiation skills & \\
$\mathbf{1 2}$ & Systematic thinking skills & \\
\hline
\end{tabular}

A total of 12 change agent knowledge elements were identified during the conceptmapping workshop. All 15 workshop participants agreed that these knowledge elements were important for anyone acting as a change agent. When the findings of the 
concept-mapping workshop were compared with the literature findings, an overlap was found with regard to the following knowledge elements: knowledge of the organisation, knowledge of change models/change principles and knowledge of change resistance theory. This overlap indicated agreement between researchers in the field and the sample group of internal change management specialists on the importance of these knowledge elements for change agents.

The change agent knowledge elements that the workshop participants agreed on are reflected in table 6 below.

Table 6

Knowledge: Results from the concept-mapping workshop and literature survey

\begin{tabular}{|c|c|c|}
\hline & $\begin{array}{l}\text { Results from the concept-mapping } \\
\text { workshop }\end{array}$ & Results from the literature \\
\hline 1 & Knowledge of the organisation & $\begin{array}{l}\text { Knowledge of the organisation, its culture and } \\
\text { customers }\end{array}$ \\
\hline 2 & $\begin{array}{l}\text { Knowledge of the organisation's external } \\
\text { environment }\end{array}$ & Process change models \\
\hline 3 & Understanding the need for change & The organisation's vision and mission \\
\hline 4 & Change management principles & $\begin{array}{l}\text { Diagnostic model of change (including } \\
\text { change principles) }\end{array}$ \\
\hline 5 & Knowledge of change resistance theories & - Resistance to change and ways to manage it \\
\hline 6 & $\begin{array}{l}\text { Knowledge of roles and responsibilities of a } \\
\text { change agent }\end{array}$ & $\begin{array}{l}\text { Overcoming barriers to change and suitable } \\
\text { communication methods and approaches }\end{array}$ \\
\hline 7 & $\begin{array}{l}\text { Understanding of the various change } \\
\text { management interventions }\end{array}$ & \\
\hline 8 & $\begin{array}{l}\text { Benefits of change and its impact on the } \\
\text { organisation and individual }\end{array}$ & \\
\hline 9 & $\begin{array}{l}\text { In-depth understanding of the specific } \\
\text { area/function where change is taking place }\end{array}$ & \\
\hline 10 & Understanding of the cycle/phases of change & \\
\hline 11 & The value of a change agent & \\
\hline 12 & Group dynamics knowledge & \\
\hline
\end{tabular}

A total of eight required elements relating to experience were identified during the concept-mapping workshop. All 15 workshop participants agreed that these elements were important for anyone acting as a change agent. The elements relating to experience that are required by change agents, as agreed upon by the workshop participants, are reflected in table 7 below.

Table 7

Experience: Results from the concept-mapping workshop

\begin{tabular}{|ll|}
\hline $\mathbf{1}$ & Expert in dealing with changing working conditions/procedures \\
\hline $\mathbf{2}$ & Exposure to implementing a change initiative \\
\hline $\mathbf{3}$ & Networking experience with those affected by change \\
\hline $\mathbf{4}$ & Consulting/Project environment-related experience \\
\hline $\mathbf{5}$ & Experience in mobilising people behind a specific goal \\
\hline $\mathbf{6}$ & Experience in dealing with conflict and different kinds of people \\
\hline $\mathbf{7}$ & Experience in having to relay harsh messages to others in a manner that instils confidence \\
\hline $\mathbf{8}$ & Facilitation experience - even if only minimal \\
\hline
\end{tabular}

The researchers could not find any literature on the experience required by change agents that could be compared with the results from the concept-mapping workshop. 
The workshop participants agreed that commitment and acceptance readiness levels were equally important when selecting people as change agents. Awareness and understanding were rated as the second most important set of requirements.

The researchers could not find any literature on the required change curve readiness levels of a change agent that could be compared with the concept-mapping workshop results.

Table 8

Change curve readiness levels:

Concept-mapping workshop results

\begin{tabular}{|l|l|}
\hline $\mathbf{1}$ & Commitment \\
\hline $\mathbf{1}$ & Acceptance \\
\hline $\mathbf{2}$ & Awareness \\
\hline $\mathbf{2}$ & Understanding \\
\hline
\end{tabular}

\subsection{Change agent identification framework}

After careful consideration and comparison of information received from literature findings, feedback from the qualitative perception questionnaire, as well as from the conversations between change management experts at the concept-mapping workshop, the following elements were identified as important dimensions for the identification of change agents:

- Willingness to act in this role. The participants indicated that participation in a change agent network should be voluntary. It should remain a matter of individual choice whether to act in this role for a specific period of time.

- Availability to perform certain tasks. The participants indicated that it would not be feasible to identify change agents to perform certain tasks if their day-to-day responsibilities did not allow them to fulfil this role. A specific percentage of their time should be allocated to their duties as change agents. Agreement should be reached between the potential change agent and his or her manager that the change agent should fulfil this role, in accordance with the agreed key performance indicators.

- Level of commitment to act as a change agent and to assist in implementing the proposed changes. The participants indicated that if someone was not committed to the proposed change initiative he or she would not carry out the responsibilities of a change agent.

- Personality traits. The participants indicated that if a person was to serve effectively as a change agent, such person required specific characteristics. In line with the literature findings, the participants agreed that the 12 personality traits to be considered when identifying potential change agents were willingness, self-awareness, approachability, open-mindedness, good listening skills, sociability, assertiveness, flexibility, integrity and honesty, perseverance, optimism and persuasiveness.

The next section comprises a discussion of the detailed insights required and the reasons for choosing these dimensions to form part of the framework.

\section{Discussion}

As mentioned previously, the four dimensions of importance in selecting change agents were identified by following a triangulation approach. Findings from the literature 
supported these four dimensions by highlighting their importance during a change agent identification process (see figure 1).

The participants at the concept-mapping workshop identified the first dimension, namely willingness, as a key consideration, since the role of the change agent must be a voluntary one. They indicated that it should be left to the individual to choose whether to fulfil this role for a specific period of time, and agreed that this was a vital dimension to consider when identifying people to act as change agents.

Participants also said that change agents should only be identified after individuals who had expressed the wish to act in this role had been given an in-depth explanation of the roles and responsibilities of change agents. Whether to accept the role of change agent should be a matter of individual choice. No person should be forced to do so. Willingness, as an element, therefore applies where people volunteer to fulfil this role.

The participants in the concept-mapping workshop noted the importance of the second dimension, namely availability, in the identification of change agents. As stated previously, they said that it would not be feasible to select people who were not able to set aside a certain percentage of their time to act as change agents. Agreement would have to be reached with a potential change agent's manager to allow the change agent to fulfil this role in accordance with the agreed key performance indicators.

The findings from the literature emphasised that the third dimension, namely commitment, could not be measured without change agents' having a comprehensive understanding of the vision, mission and objectives of the transformation programme (Rice, Eggleton, Eggleton \& Rice 1996).

In the research conducted by the above authors into high-performing teams, one of the focal areas was measuring commitment. Senge (1990) conducted extensive research on different levels of commitment and developed a model to help learning organisations to measure commitment in terms of a specific mission or vision and objectives. Senge points out that almost $90 \%$ of the time, commitment is confused with compliance.

Today, it is common to hear management talking about obtaining "buy-in" from their employees into the vision or mission. "Enrolment" is another key term in this context, because the change agent will "enrol" to act as such. Senge observes that enrolment entails both free choice and a process, and that when it comes to real commitment to a particular vision or mission, there are still many contemporary organisations in which only a few people are enrolled and even fewer are committed. Senge (1990) therefore indicates that there are a number of different levels of compliance that result in behaviour such as enrolment and commitment.

Participants at the concept-mapping workshop said that if someone was not committed to the proposed change initiative, he or she would not fulfil the responsibilities required of a change agent. They agreed that this was a vital dimension to consider when identifying individuals as change agents.

The fourth dimension of the framework, namely personality traits, also originated in findings from the literature. For the purposes of the empirical research conducted, it was of crucial importance to understand the ideal personality traits of change agents, in order to ensure that people are identified as potential change agents on the basis of suitable characteristics. For the purposes of this research, the ideal profile refers to the ideal personality traits that someone requires in order to be identified as a change agent with the ability to drive and manage change in his or her business. 
Figure 1

Change agent identification framework

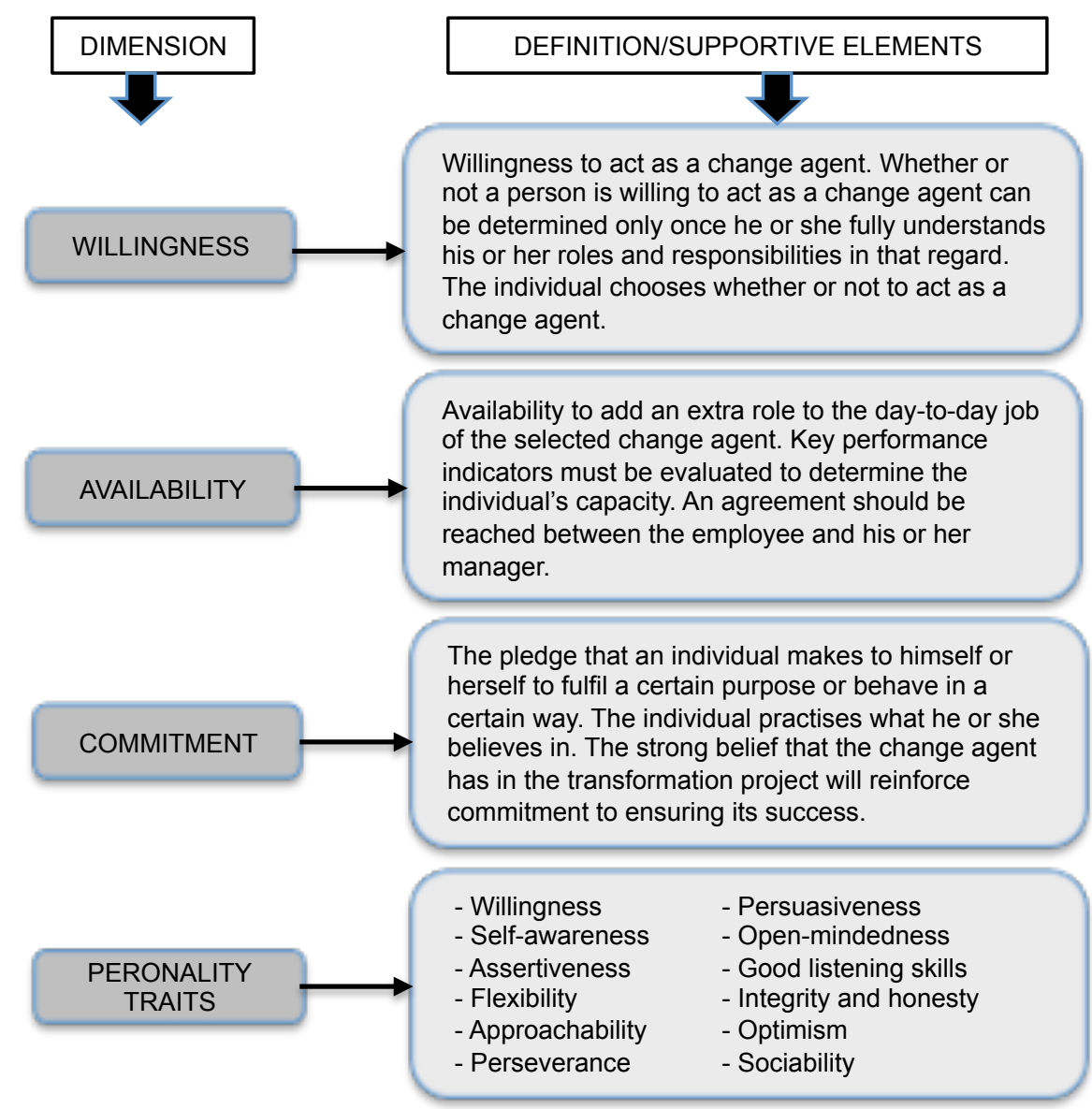

Source: Van der Linde-de Klerk 2010

As stated previously, the workshop participants emphasised the importance of change agents' being directly affected by the change initiative so that they could identify with the problems of co-workers and explain the potential advantages of the change. This would enable the change agents to influence their peers to accept change and provide feedback to the change management team on possible concerns. A rigorous qualitative research process was followed in establishing the theoretical framework, which could prove useful for industrial and organisational psychologists specialising in change management in organisations undergoing change.

Although existing questionnaires were found, which are currently being used by organisations to identify change agents, no other theoretical or empirical framework appears to have been developed, either locally or internationally. Therefore, this is considered to be the first framework to be developed as a guideline for identifying change agents in organisations.

The research project can therefore be considered to have achieved its primary objective of developing a change agent identification framework. 


\section{Limitations and recommendations for future research}

The research was limited by the following: For reasons beyond the control of the researchers, a total of 73 change agents left the change agent network during the transformation process, thus leaving only 27 change agents. A larger sample group would, have been more valuable.

Only a limited number of sources were found dealing with the concept of "change agent". Little information was available on the roles and responsibilities of change agents and the methods or tools used in the past to identify change agents. No biographical information, such as age, gender, race or level of education, was taken into account in determining the criteria for selecting change agents. This information could have contributed to even more stringent selection criteria. These factors did not necessarily influence the empirical results, but were noted with the observations that could have had an impact on the overall research results.

This study identified the need for further research, as well as the expansion of the theoretical knowledge base on the concepts of change agent and change agent identification. Possible areas for further study and the expansion of the theoretical knowledge base are indicated below:

- Future research could be conducted on change agent networks and identification tools to expand the knowledge base.

- A validated change agent identification tool could be developed in the form of a questionnaire to help organisations to make the right choices.

- Similar research could be conducted in a large organisation involving a larger sample group of change agents.

- Researchers could make a detailed study of the way change agents function at their organisations and share this information with other specialists in other organisations. This would help to grow the concept of change agents.

- Organisations could appoint individuals as change agents and determine the real value of these properly identified individuals and their contribution to overall project success by measuring their influence on employee changereadiness levels.

- It is recommended that all four dimensions in the framework should be tested at the beginning of the next change agent identification process.

- Similar research could be conducted internationally, as this would contribute significantly to global change agent research.

- In future, once change management practitioners have determined the skills, knowledge and experience levels required, change agents could be more appropriately equipped to manage change in their respective areas of a business.

- It is recommended that the organisation at which this research was conducted should use the change agent identification framework developed to guide future change management consultants in identifying change agents.

\section{Conclusion}

Although a number of questionnaires and methods that are currently used by organisations to identify change agents were found, no formal and holistic change agent identification framework was found in the existing body of knowledge - in either previous empirical research or in the literature findings. To date, there has been no 
scientific research to determine the characteristics of change agents in large organisations by means of a qualitative and/or quantitative process. In the past, most findings on this topic were perception-based. The findings of the current study are merely a beginning - as a great deal still remains to be investigated. The change agent concept is still evolving, and all the intricacies of this role in a project-related environment are not yet fully understood. It is trusted that this study has contributed to the body of knowledge pertaining to the field of change management in industrial and organisational psychology.

The research findings contributed towards a comprehensive understanding of the role of change agents, as well as the elements that make up a framework for selecting change agents. Managers and employee relations practitioners are constantly involved in the coordination and management of change and have to rely on change agents to facilitate change initiatives. They could make good use of the proposed framework in selecting change agents with the required characteristics. A further advantage of the framework is that it will ensure that the selection process is perceived as fair by colleagues and union representatives.

There is nothing wrong with change, if it is in the right direction.

Winston Churchill

\section{List of references}

Accenture. 2007. The change agent handbook. Johannesburg: Accenture.

Arrata, P, Arnaud, D, \& Kumra, G. 2007. Building an effective change agent team. Available at: http://web.ebscohost.com/ehost/detail (accessed on 09 January 2008).

Bolognese, AF. 2002. Employee resistance to organisational change. Available at: www.newfoundations.com/OrgTheory/Bolognese721.html (accessed on 26 June 2007).

Borysowich, C. 2006. Hiring roles: The change management specialist. Available at: http://it.toolbox.com/blogs/enterprise-solutions/hiring-roles-the-changemanagement-specialist-10763 (accessed on 09 July 2012).

Burke, WW. 2002. Organization change: Theory and practice. Thousand Oaks, CA: Sage.

Burnes, B. 2004. Managing change. 4th edition. Harlow, Essex: Pearson Education.

Canterucci, J. 2000. Are you a change leader? Available at: www.corpchange.com/ archives/article/article_archives/a19_are_you_a_change_leader (accessed on 2 October 2007).

Cheung, C, Jurman, S, Maguigad, A, \& Slaughter, A. 2007. Leaders as change agents. Leadership APTA Class of 2007.

Creswell, JW. 1994. Research design: Qualitative and quantitative approaches. Thousand Oaks, CA: Sage.

Creasey, T. 2007. Defining change management. Available at: http://www.changemanagement.com/Prosci-Defining-Change-Management.pdf (assessed on 05 June 2012).

De Caluwé, L \& Vermaak, H. 2002. Prevailing perspectives on change. Paper submitted to Management Consultancy Division, Academy of Management, for the 2002 Conference in Denver, Colorado. 
Doyle, M, Claydon, T \& Buchanan, D. 2000. Mixed results, lousy process: The management experience of organisational change. British Journal of Management 11: $59-80$.

Dunphy, D \& Stace, D. 1993. The strategic management of corporate change. Human Relations 46(8):905-918.

Ford, JD \& Ford, LW. 1994. Logistics of identity, contradiction, and attraction of change. Academy of Management Review, 19(4):756-785.

Hailey, VH. 2001. Breaking the mould? Innovation strategy for corporate renewal. Human Resource Management 12(7):1126-1140.

Hayes, J. 2002. The theory and practice of change management. Wiltshire: Palgrave.

Huber, GP \& Glick, WH. 1993. Organisational change and redesign. New York: Oxford University Press.

Hutton, DW. 1994. The change agents' handbook. New York: American Society for Quality.

Katzenbach, J. 2008. Effective change leaders. Available at: www.mallenbaker.net/ csr/CSRfiles/effective.html (accessed on 29 February 2008).

Keep, E \& Mayhew, TA. 1995. Training policy for competitiveness: Time for a new perceptive. London: Policy Studies Institute.

K Jha, S. 2007. Organizational behaviour: Personality and attitudes. Available at: http://obreader.blogspot.com/2007/11/ob-handout-3.html (accessed on 09 February 2008).

Laycock, M. 2002. Module 1: Dealing with change. Available at: www.oznet.ksu.edu/ LEADS/FACT \%20sheets/EP91.pdf (accessed on 27 August 2007).

Massey, L \& Williams, S. 2006. Implementing change: The perspective of NHS change agents. Leadership and Organisational Development Journal 27(8):667-681.

McNamara, C. 2007. Basic context for organizational change. Available at: http://www.managementhelp.org/mgmnt/orgchnge.htm (accessed on 15 November 2007).

Mitchell, JG \& Young, S. 2001. High-skilled high performing VET. Melbourne: ANTA.

Moran, WJ \& Brightman, BK. 2000. Leading organisational change. Journal of Workplace Learning: Employee Counselling Today 12:66-74.

Morgan, N. 1996. 9 tips for change agents. Fast Company 5,124

Mott, J. 2000. Change agent. Washington DC: William Rainey Harper College.

Mouton, J \& Marais, HC. 1994. Basic concepts in the methodology of social science. Pretoria: Human Sciences Research Council.

Neuman, WL. 2002. Social research methods: Qualitative and quantitative approaches. 4th edition. Boston: Allyn \& Bacon.

Paton, RA \& McCalman, J. 2000. Change management: A guide to effective implementation. 2nd edition. London: Sage.

Perme, C. 1999. Agents of change. CM. Perme \& Associates 8(1). Available at: http://www.cmperme.com/pdf/cmp9906.pdf (accessed on 10 July 2012).

Pettigrew, A \& Whipp, K. 1991. Managing change for competitive success. Oxford: Blackwell. 
Porras, JI \& Robertson, PJ. 1992. Organizational development: Theory, practice, research. Handbook of Organizational Psychology 3:719-822.

Powell, MK. 2002. Motivation: Organization change. In: WW Burke (ed): Theory and practice. Thousand Oaks, CA: Sage.

Powers, M. 2003. Key role: The change agent. Available at: http://www.nasconsulting. biz/pdfs/TCS.pdf (accessed on 10 January, 2008).

Quy Nguyen, H. 2001. Time, temporal capability and planned change. Academy of Management Review 26:602-620.

Recklies, D. 2001. What makes a good change agent? Available at: http://www. themanager.org/Strategy/Change_agent.htm (accessed on 29 November 2007).

Rice, J, Eggleton, C, Eggleton, CH \& Rice, JC. 1996. The fieldbook of team interventions: Step-by-step guide to high performance teams. Amherst, MA: Human Resources Development Press.

Robbins, SP. 2005. Organizational Behaviour. 11th edition. Upper Saddle River, NJ: Prentice Hall.

Rogers, EM. 2003. Diffusion of innovations. 5th edition. New York: Free Press.

Rogers, EM \& Kincaid, DL. 1987. Diffusion of innovations. 3rd edition. New York: The Free Press.

Rouse, M 2009. Organizational change management. Available at: http://searchciomidmarket.techtarget.com/definition/change-management (accessed on 30 May 2012).

Ryan, M. 2011. Research in a minute: Probability vs. non-probability sampling. Available at: http://blog.insightexpress.com/2011/01/research-minute-probability-vsnon- probability-sampling (accessed on 05 June 2012).

Saka, A. 2003. Internal change agents' view of the management of change problems. Journal of Organisational Change Management 16(5):490-496.

Schein, HA. 1987. Process consultation: Its role in organisational development. Reading, MA: Addison-Wesley.

Senge, P, Kleiner, A, Roberts, C, Roth, G, Ross, R \& Smith, B. 1999. Dance of change: The challenges of sustaining momentum in learning organisations. New York: Doubleday.

Senge, PM. 1990. The fifth discipline: The art \& practice of the learning organization. New York: Doubleday.

Smith, I. 2005. Achieving readiness for organisational change. Library Management 26(7):408-412.

St-Amour, D. 2001. Successful organisational change. Canadian Manager 26(2): 20-22.

Stassen, T. 2006. Change Management. Available at: http://www.changewright.com/ on\%20cange.htm (accessed on 10 August 2007).

Strebel, P. 1998. The change pact. San Francisco: Biddles.

Tan, A \& Kaufmann, UH. 2000. Making good change agents: Attitudes and skills. Available at: http://europe.isixsigma.com/library/content/c040501a.asp (accessed on 29 February 2008). 
Tearle, R. 2007. The role of a change master: From change agent to change master. Available at: http://www.changedesigns.co.za/The_role_of_a_change \% 20master.htm (accessed on 16 October 2007).

Ticky, NM \& Devanna, MA. 1990. The transformational leader. 2nd edition. New York: Wesley.

Trochim, W. 2002. Non-probability sampling. London: Routledge.

Turner, DM. 2012. Do you know where you are going? Defining an intended outcome for change. Available at: http://www.thinktransition.com/organizational-changearticles/77-defining-change.html (accessed on 29 May 2012).

Van de Ven, AH \& Poole, MS. 1995. Explaining development and change in organizations. Academy of Management review 20(3):510-540.

Van der Linde-de Klerk, M. 2010. The development and validation of a change agent identification framework. Unpublished DCom thesis. Pretoria: University of South Africa.

Van Tonder, CL. 2004. Organisational change: Theory and practice. Hatfield: Van Schaik.

Welch, J \& Welch, S. 2008. What are change agents made of? Available at: http://www.businessweek.com/magazine/content/08_42/b4104096917161.htm (accessed on 29 May 2012).

Wertheimer, MSW. 2001. The change agent's tool box. Core qualities of change agents. Available at: www.nasmhpd.org/general_files/publications/ntac_pubs/ toolbox/agent8.html (accessed on 16 October 2007).

Worren, NAM, Ruddle, K \& Moore, K. 1999. From organizational development to change management: The emergence of a new profession. The Journal of Applied Behavioral Science 35(3):273-286. 